\title{
AC 2008-2878: COMPUTER APPLICATIONS FOR ENGINEERS : TEACHING ORGANIZATIONAL, PROBLEM SOLVING AND CHECKING SKILLS TO FRESHMEN ENGINEERING TECHNOLOGY STUDENTS
}

\section{David Forsman, Pennsylvania State University-Erie}

David R. Forsman is a Senior Lecturer in Engineering at Penn State Erie. He received his B.S. in Engineering Technology from the Pennsylvania State University and his M.E. in Manufacturing Systems Engineering from SUNY, Buffalo. He has been involved with engineering computer analysis since 1974. He has experience in teaching Computer-Graphics, Programming, CAD and Rapid Prototyping for the last 23 years. 


\title{
Computer Applications for Engineers : Teaching Organizational, Problem Solving and Checking Skills to Freshmen Engineering Technology Students
}

\begin{abstract}
:
Students in Engineering Technology programs usually are required to take some sort of computer course, such as a programming or an applications course their first semester. A significant number of these students feel they are qualified to solve problems using a computer as a tool based on a prior high school course in Excel or simply because the traditional college freshmen is steeped in the use of the Internet and has played video games. However, many of these students generally do not realize that they have not developed the study, organizational or problem solving skills required for effectively solving engineering programs with computer technologies.
\end{abstract}

This paper will describe the methods used to teach a Computer Applications for Technologists course using Excel and Mathcad. The paper will detail the methodologies developed for teaching students to effectively write a spreadsheet using Excel and develop a worksheet for Mathcad. The requirement of using different programs to produce exactly the same result for the same problem forces students to become involved in self learning in the sense that they can no longer simply accept partial credit for incorrect work as if they did not know the answer was wrong. They must now develop the skills to determine if the answer is somewhat plausible, and for most students, to learn how to analyze, test and debug their programs in order to produce what they know is the correct result. The net result are students that are capable of using Excel and Mathcad effectively as a tool for future courses as well as having the ability to recognize and correct problems on their own.

Introduction:

MET 107, Computer Applications for Technologists is a first semester freshman course that meets for one hour fifty minute periods, twice a week for fifteen weeks. The course structure is basically a half hour demonstration/lecture on a specific topic with the rest of the class period devoted to a hands on work session. This course assumes no prior knowledge of any application software, but does require that the students have a background in a computer operating system so that they are familiar with files, folders and starting applications.

The course objectives are as follows:

1. Create technical documents containing properly formatted text, figures, drawings, tables, graphs and/or equations using Microsoft Office products;

2. Create properly formatted worksheets to solve basic engineering problems through the use of cell formulas and functions;

3. Create formatted graphs of one or more data series using spreadsheet software;

4. Use worksheet tools and techniques to solve equations, systems of equations, maximum and minimum of a function, the roots of a function and areas using the trapezoid rule;

5. Record and use custom macros in a spreadsheet program; 
6. Use text, equation and graph regions in MathCad to solve engineering problems;

7. Display proper units with quantities in MathCad worksheets;

8. Use MathCad to solve equations numerically and symbolically;

9. Create a computer slide presentation containing properly formatted text, figures, drawings, charts, tables, graphs and/or equations using Microsoft Office products

This course relates to our TAC-ABET program outcomes as follows: Students should be able to identify and use appropriate computer technologies during the solution of applied engineering problems

What is not specifically stated as a course objective, although it basically assumed, as in all courses, that students will develop the ability to determine if their result is reasonable and to check their work using independent methods.

In the past, various attempts were made to convince the student that they need to be held accountable for their work using different methods. Assigning problems that are subsets of leaning activities from future courses such as statics and strength of materials with the hope that students might pay more attention and put additional effort into their work has only met with moderate success at best. Various assignment groups had percentage values changed so as to place more emphasis on them with the hope that students would then take them more seriously. This ended up being too abstract and did not impact the learning process.

Background:

Times have changed. If you have been around engineering education long enough you have seen a shift in student attitudes towards computers and their use. Twenty plus years ago it was unusual to have a student with any computer skills. At that time students might openly state that they had no use for computers and really didn't want to be involved with their use. Today, it is almost the opposite. Students have grown up with electronic devices and at times feel that the older generation is the one out of touch with (electronic) reality. Hipp and Addison state "professors are hardly 'introducing' them to computers, rather, they are showing new applications" and the fact that students are "inoculated into a cookbook approach to software". (1) By the same token, even though students spend an average of 11 to 15 hours using computers each week ${ }^{(1)}$ the number of students who have formal information technology training is low and view it as dull. ${ }^{(2)}$

Traditionally, technology students took a traditional computer programming class that was Fortran based. The Fortran programming later was supplemented with Basic programming as PC's became more prevalent in the engineering workplace. Starting in 1999, the required course in programming was changed to a computer applications course for technology students. The subject material included a small component using Word to produce common engineering type documents. Topics such as equations, bulleted and numbered lists, tables and using drawing tools were included with the normal word processing items. The main topics in the course had to do with solving engineering problems using Excel. Producing charts, using math, trig, logic, lookup, matrix, text and statistical functions as well as being able to use goal seek and solver and doing simple numerical integration using the trapezoid method were covered. Meetings and 
discussions with the Engineering Advisory Board for the program pointed out the need for our students to be acquainted with higher level software products that could be used to perform and document engineering calculations. Mathcad was chosen to fulfill that need. At that time, the Mathcad topics were fairly limited and relegated to four class periods at the end of the semester.

In the last few years it had become apparent that the use of Mathcad should be expanded as students were (on their own) discovering how useful the tool could be in upper level courses such as Heat Transfer and Fluid Power. At the same time it was realized that essentially doing a full integration of Mathcad into the Computer Applications for Technologists course could benefit these students in the sense that could check their Excel solutions with Mathcad and begin to learn how to correct their own mistakes.

Students had been hearing throughout grades school and high school about how they need to learn something because they are going to need it "later". For the most part, they really haven't needed it "later", and if they did it was re-taught. Since students taking this course are freshmen, most of the example problems in the course are pulled from subjects they will be covering in coming semesters. The basic knowledge (physics, algebra, and trigonometry) that they were going to need "later" suddenly has become "now" in order to understand and execute solutions using a computer. This is somewhat of a revelation to many students and this issue is really not unique to a course in computer methods, but does impact student performance.

At the start of the fall 2007 an informal survey was taken at the beginning of the course: all 66 students were familiar with and had various degrees of exposure to Microsoft Word and Excel. No student had ever used Mathcad.

In the past, this course was taught with a short lecture then a demonstration of techniques at which time the students would begin to produce a solution to a given problem using methodologies presented earlier. Unfortunately, most students would spend a disproportionate amount of class time working on the format of the spreadsheet, rather than dealing with the issues requiring higher level thinking. Few students were able to finish an assignment in the remaining class time most students ended up having to deal with the more difficult concepts on their own.

The class is never taught on consecutive days; generally speaking, students would not continue to work on the assignment the same evening as they had class. This meant that they could not come to the instructor's office the next day and ask questions. They would wait until the night before the assignment was due to continue to work on it. Couple this with the fact that first semester students don't have a feel for whether their final solution is even in the ball park relative to being correct or not and you have the makings of a homework assignment that will require a lot of time in grading. Students would turn in incorrect work, instructors would mark it up and return it only to have students look at the grade and file it away not really being interested in correcting what they had done wrong. Should instructors require students to correct the work and re-submit it in before giving students partial credit? In a perfect world, the answer would be yes. This was tried, but unfortunately it turned into a logistical nightmare. It is bad enough trying to turn around 60 homework assignments after each and every class period, but to almost 
double that in checking to see if students actually made the corrections made life miserable for all concerned.

There had to be a better way of getting students to take on some of the responsibility for their own actions and learning without increasing instructor workload.

A minor overhaul or redesign of this course seemed to be in order to accomplish the following five goals:

1) Convince students to take more ownership of the class and their own learning;

2) Teach the students the value of being able to check their own work using an independent method;

3) Increase student's ability to use Mathcad (Knowledge in Excel was not an issue);

4) Keep the student workload from increasing.

5) Keep from increasing (if possible) the faculty workload as school enrollments have been steadily increasing resulting in more sections of the class needing to be taught.

Step 1: Bringing Students Back to Reality

Sometime you think that it would be a good thing to ease student into the college life. This course starts off with three periods of the use of Word. These periods are spent on topics in Formatting, Tables and Drawing Tools. Another class period is spent on PowerPoint. Of course there is nothing very challenging in regards to any of these topics, and the vast majority of students have extensive high school experience in using these products. After two weeks of low level activity students quickly develop the idea that this particular course is an extension of high school; more review and not an awful amount of higher level thinking required.

Before covering any Excel or Mathcad topics, two periods are spent in problem solving. Most students have never had to actually develop software or solve fairly complex - open ended problems. The concepts of having to Analyze, Design, Implement and Install are totally foreign to them. Plan; Determine unknowns; What needs to be found; What fundamentals apply; Develop a solution; what is with all that? Don't you just DO things? Can't you just trial-anderror applications until you get the desired result?

Input - Transformation - Output (ITO) charts, Flowcharts and Psudo-Code appear to be just more busy work when introduced to the students.

Students are asked to come up with an algorithm in ITO chart format for computing the surface area and volume of a simple block that has material removed. There is a lot of eye rolling by the students when it suggested that it is more difficult than it appears on the surface. The assignment is presented as follows on the next page. 
MET 107

Homework 5a, Algorithm Development

Problem:

Develop a generic algorithm that computes the volume $(\mathrm{V})$ and surface area $(A)$ of a rectangular prism as shown. The center of the radius will always be located at the intersection of the front and left vertical faces. Include error handling in the sense that $\mathrm{R}$ can never be greater than $\mathrm{T}$.

(Students are given specific numeric input and a list of equations for area and volume; this information has been deleted.)

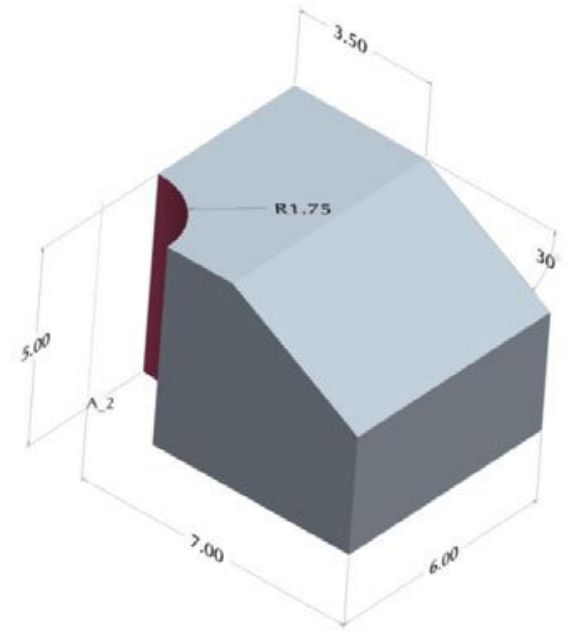

Produce an ITO chart of your algorithm. This must be done using a table in Word.

Make sure that you use symbolic (variable) names when producing this chart.

Do not combine intermediate formulas together!

You need to use a trig function to calculate intermediate linear dimensions.

After printing your ITO chart, make a copy of it and substitute the actual values show above replacing all your symbolic variables.

Re-print your ITO chart showing the numeric result.

Example:

Symbolic Version:

Numeric Version:

\begin{tabular}{|l|l|l|}
\hline & $\begin{array}{l}\text { Calculate area one } \\
\text { area1=dist }{ }^{*} \text { dist2 }\end{array}$ & \\
\hline $\begin{array}{l}\text { Calculate area two } \\
\text { area2=dist1*dist3 }\end{array}$ & \\
\hline $\begin{array}{l}\text { Calculate total area } \\
\text { areaT=area1+area2 }\end{array}$ & \\
\hline
\end{tabular}

\begin{tabular}{|l|l|l|}
\hline & $\begin{array}{l}\text { Calculate area one } \\
\text { area1 }=10^{*} 20=200\end{array}$ & \\
\hline & $\begin{array}{l}\text { Calculate area two } \\
\text { area2 }=10^{*} 30=300\end{array}$ & \\
\hline & $\begin{array}{l}\text { Calculate total area } \\
\text { areaT }=200+300=500\end{array}$ & \\
\hline
\end{tabular}

This assignment appears to be the first reality check for our technology students. Of the students that complete the assignment the average grade is $78 \%$. $15 \%$ of students have it fundamentally correct. $32 \%$ of students do not turn in the assignment at all as they are unable to complete it satisfactorily. Some students managed to compute volumes of the order of $1 \times 10^{6}$ and think nothing of it given the initial overall dimensions of $7 \times 6 \times 5$ units. By the third week of the semester, students have enough background in their CAD course that they could model the shape and compute the mass properties of it as an independent check of their work. Very few students do this.

At this point students begin to see the value of planning and working on a project in a timely manner. In this particular case not waiting until the night before something is due to begin serious work on the assignment. Some students seem embarrassed by the fact that they could not correctly develop an algorithm for such simple geometry. "Both less experienced and more experienced students have a tendency to significantly over-estimate their computer competence". (2) 
Step 2: Trying to get Students Organized:

There are two components to this topic. The first has to do with physical artifacts related to the course. There is no textbook associated with this course. The college has switched to Office 2007 products and there were no engineering based Excel texts based on the latest version of Excel that were suitable for reference use. This means that the entire course is web based regarding student reference material. This course can be found at:

http://engr.bd.psu.edu/forsman/ Students typically printed out the lecture and homework assignments from the web pages. When students included documentation produced for the homework assignments the course completely fills a two inch - three ring binder. Quizzes and Exams are open book/computer. Students who are disorganized find it difficult to locate references to needed material during these times. We attempt to teach students that it just as important to know where to find information as it to know something, as you cannot know everything

The second issue organizational issue is getting students to understand that they have to be organized enough to not wait until the last minute so start something. Time management is critical in being successful, especially when relying on technology for solving problems. Students quickly realized the folly in waiting until essentially the last minute when working on course assignments that were coupled. Hardware and software issues as well as simply running into a simple interpretation issue related to the assignment are always out there waiting to snare the unsuspecting student. Late work would be accepted (marked down 10\%), but this work would only be accepted until grading was completed for a particular assignment. In practice this meant that students had to have work turned in by the next day at the latest as grading of their current assignments would be started almost immediately after submittal. In practice almost no students attempted to turn in late work. The few that did invariably found that the previous work had already been graded as student work was always ready to be returned the following class period.

Step 3: Holding Students Responsible for their Actions:

How do you get students to learn that they should be turning in fairly complete, well thought out and verified solutions to assignments that have been given to them?

After careful consideration, it was decided that coupling assignments given in Excel with Mathcad would be the best way to accomplish these goals.

What this means is as follows:

1) Students would solve a given set of problems using Excel during the Tuesday class period, not submitting their work for grading.

2) Students would solve the same problem set using Mathcad during the Thursday class period.

3) Students would include a summary sheet that must be filled out and included with student documentation for both Excel and Mathcad. This documentation set would be turned in during at the start of the next class period; the following Tuesday. 
While the following singular examples spans four pages in this document, it is critical that the reader have an overview of an assigned problem set in order to put the discussion in the proper context.

\section{Excel Problem:}

MET 107

Homework 25 - Solver \& Goal Seek

Often times in engineering, it is necessary to solve equations simultaneously or to find the minimum or maximum value of a function. This homework utilizes Solver and GoalSeek to solve these kinds of problems. Prepare your worksheet in an organized fashion so that I will be able to follow your work. Include necessary text in cells so that I can tell that you did the work properly.

(Student instructions deleted in this region)

Graph the following functions on a single XY(Scatter) chart in Excel:

$y=2 x^{2}+4 x-10$

$y=-2 x-1$

(Formatting instructions deleted)

In the worksheet, use Solver to find the coordinates of the intersections between the line and the parabola. You will have two screen captures of the Solver Dialog box, as there are two sets of coordinates which define the answer.

In the worksheet, use the Solver tool to find the coordinates of the minimum value of the parabola.

Use Goal Seek (two times) to find the roots of the parabola. Remember that a root is the x-value that causes a function to have a $y$-value of zero (in other words, at what values of $x$ does this function intersect the $x$ axis). You must check this answer by doing hand calculations using the quadratic formula.

Side note: For a function having the form $a^{2}+b x+c=0$, the values of $x$ can be determined by the quadratic formula which states:

$$
X=\frac{-b \pm \sqrt{b^{2}-4 a c}}{2 a}
$$

Print your worksheet. Be sure that your name and identifying information is printed on your documents. Show gridlines and headers on the worksheet pages. You will have five screen captures imbedded in your spreadsheet.

Solve the following problem by using Solver to solve simultaneous equations:

A swimmer wishes to start on one side of a fast moving river and swim across the river, ending at a predetermined point on the other side.

Assuming that you know the width of the river, how far down river the swimmer needs to go, how fast the swimmer can swim and the velocity of the current, find the angle the swimmer must take to minimize the time in the water.

You intuitively know the following:

The horizontal distance covered is equal to the Horizontal Velocity of the swimmer * Time in the water. The vertical distance covered is equal to the Vertical Velocity of the swimmer * Time in the water plus the Velocity of the current ${ }^{*}$ swimmer time in the water. 
Refer to the information below for setting up your worksheet. Use the reading showing solving simultaneous equations (landscape format) to guide you in this solution. Make sure you include the screen capture of the Solver dialog box.

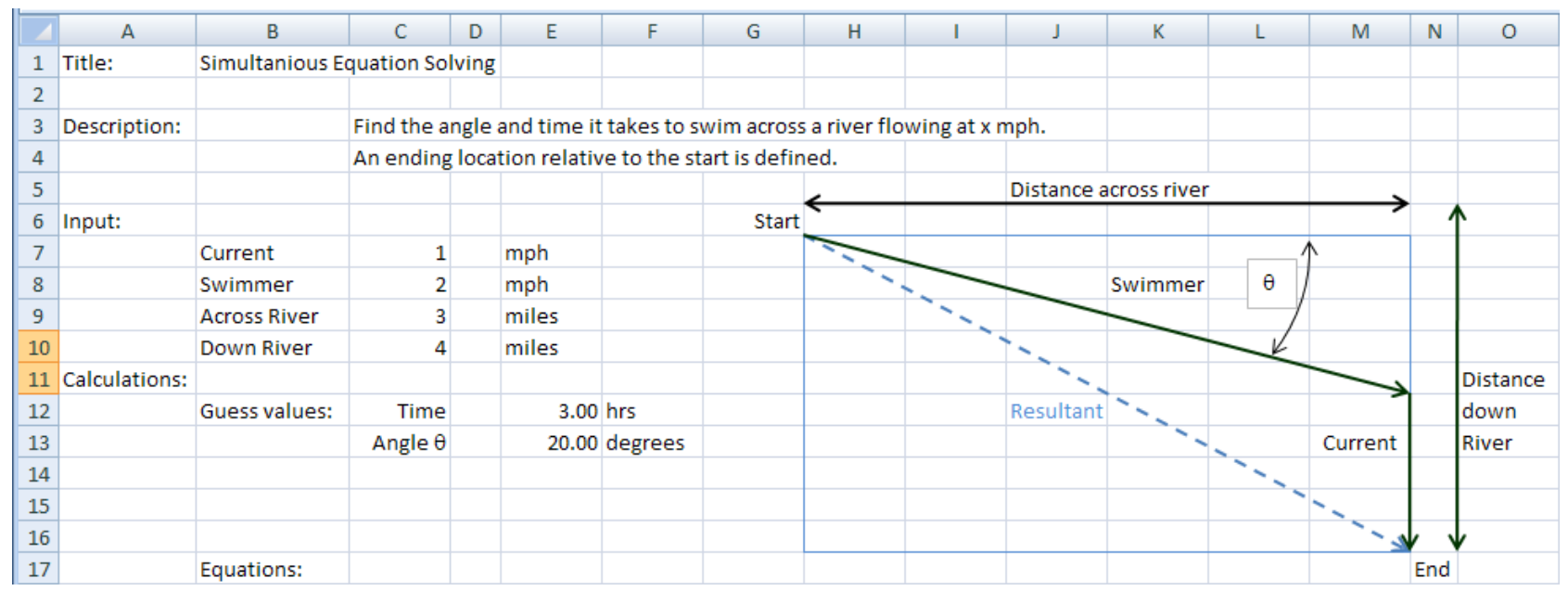

Print both the spreadsheet and the equations using the two special functions macros.

Using the Law of Cosines and Solver: Given an equilateral triangle with the indicated lines and lengths, determine the interior angles as well as the length of the sides. Hint: all the values of "c" must be the same (think constraints) and the sum of the interior angles must equal 360 (think target cell).

Set up your worksheet as follows (include a screen capture of the Solver dialog box):



Print both the spreadsheet and the equations using the two special functions macros. 
Mathcad Problem:

MET 107

Homework 26 - Mathcad

Refer to Homework 25 for Excel.

- Create a chart showing the two functions.

Evaluate the function at intervals of .5 so the curve is smooth

Select the Crossed Axis Style (Format)

In all cases, box your answers.

- Use Find to determine the two intersections between the line and the parabola.

- Use Minimize to determine the minimum value of the parabola.

- Use the root function to determine both roots of the parabola.

- Use the solve function to determine both roots of the parabola.

- Use the Quadratic Equation to determine both roots of the parabola.

- Solve the swim across the river problem using Find.

- Solve the law of cosines problem using Find.

Student Documentation (submitted for grading):

- Chart1 (1 page)

- Worksheet for two functions problem (Note: no need to document cell formulas with macro) (1 or 2 pages)

- Hand calculations for quadratic equation (1 page)

- Worksheet for swimmer problem using both special functions macros (2 pages)

- Worksheet for law of cosines problem using both special functions macros (2 pages)

- Mathcad solutions (X pages)

- Summary Sheet Excel/Mathcad (1 page) 
A pre-formatted summary sheet was given to the students to fill in as follows:

Summary Sheet - Homework $25 \& 26$

Excel / Mathcad Comparison

\begin{tabular}{|c|c|c|c|c|c|c|}
\hline Intersecting Functions & $x$ & $Y$ & $x$ & $\mathrm{Y}$ & Check & Explanation if not exact match \\
\hline \multicolumn{7}{|l|}{ Excel } \\
\hline \multicolumn{7}{|l|}{ Mathcad } \\
\hline Minimum Values & & $Y$ & & & & \\
\hline \multicolumn{7}{|l|}{ Excel } \\
\hline \multicolumn{7}{|l|}{ Mathcad } \\
\hline Roots & $x$ & & $x$ & & & \\
\hline \multicolumn{7}{|l|}{ Excel } \\
\hline \multicolumn{7}{|l|}{ Mathcad root } \\
\hline \multicolumn{7}{|l|}{ Mathcad Solve } \\
\hline \multicolumn{7}{|l|}{ Mathcad Quad Eq } \\
\hline Swimmer Problem & Time & Angle & & & & \\
\hline \multicolumn{7}{|l|}{ Excel } \\
\hline \multicolumn{7}{|l|}{ Mathcad } \\
\hline $\begin{array}{l}\text { Law of Cosines } \\
\text { Problem }\end{array}$ & alpha & beta & gamma & c & & \\
\hline \multicolumn{7}{|l|}{ Excel } \\
\hline Mathcad & & & & & & \\
\hline
\end{tabular}

$$
\begin{aligned}
& \mathbb{0} \\
& \stackrel{\mathscr{O}}{\mathbb{D}} \\
& \vec{\omega} \\
& \dot{\omega} \\
& \mathbb{N} \\
& \dot{\vec{\Xi}}
\end{aligned}
$$


Perceived Results:

Projects given using the above format (one class Excel, the next class solving the same problems using Mathcad during the same week) accomplished the following:

I) Made students responsible for their own learning

A. Even though the students might not know if the solution to a problem was correct using Excel, if they did not get the same result using Mathcad they had a pretty good idea that either one or the other methods were incorrect.

1. It was the student's responsibility to determine where they went wrong. There were severe penalties imposed if results for both methods did not match and there was not a good explanation of the discrepancy. While it is common sense that should only be one correct answer to a closed end problem, students seem to need to be taught that in industry that producing that singular, correct answer is important.

2. Students had ample time to find and correct any discrepancies in their work as they would generate Mathcad results on Thursday and didn't have to turn in the documentation until the beginning of class on the following Tuesday.

II) Student understanding and utilization for each package increased

A. When results did not match, the students had to analyze what they did using each package to understand why results were different.

B. Bouncing back and forth from Excel to Mathcad increased utilization over solving for an answer one time and then moving on.

III) Student workload remained the same.

A. Three periods spent on Word topics (no change).

B. One period spent on PowerPoint (no change).

C. Seven periods spent on stand-alone Excel assignments

D. Three of the original Mathcad periods were incorporated into coupled assignments.

E. One original Mathcad period was still taught as stand-alone.

F. Four select (maybe redundant) topics in Excel were removed and replaced with Mathcad topics resulting in fourteen class periods that had coupled Excel/Mathcad assignments (7 sets).

IV) Overall instructor time spent grading remained about the same considering that additional sections were added.

A. Instructors could not simply look at the summary sheet as students had a tendency to simply duplicate results when filling the sheet in. If the accompanying documentation did not match what was on the summary sheet, students immediately lost $30 \%$ of the assignment grade.

B. There seemed to be less reliance on the student hoping for partial credit as a blank space in the summary sheet was a bold reminder to the student that a task wasn't completed and no credit should be given. 
Student Comments Related to Problem Solving:

At the end of each semester, all students in every class fill out anonyms (written) comment sheets as well as filling in a computer scored bubble sheet relating to student perceptions of the course ranking the class relative to other courses they have taken.

At interest are the unsolicited comments that students produced during the last semester that this course was taught. $21 \%$ of students made comments related to problem solving skills. Examples of comments where "figuring out how to solve a problem on your own"; "learning how to solve a problem"; "builds problem solving skills" etc.

Interpretation of Student Comments:

What is significant is in the past there have been almost no comments related to problem solving. Instructor perception of prior semesters suggested that students were simply jumping through hoops in order to "get their ticket punched", and were not getting what they could have out of the course. This appears to have changed a bit based on student written responses.

\section{Student Grades:}

If final grades are used as an indication of whether changes made to a course has "improved" the course or not, we would be hard pressed to be able to quantify the results of the recent changes. Final course grades have remained relatively constant over time. The last three years have resulted in average final course grades of 79, 80 and 79 percent. Components that make up the grade distribution (homework/quizzes/exam) as well as complexity of the final exam have changed over the years making a purely objective determination impossible.

There are also issues in determining if in fact student problem skills have increased. This would be something that would be difficult to measure or quantify. About the best we can do is observe student behavior and make subjective determinations related to how students deal with problem solving issues. What questions students ask as well as how they ask these questions usually lends some insight into the progress the students are making towards being effective problem solvers. No exam or quiz questions could possibly quantify this.

\section{The Next Step:}

Given the fact that significant strides were made in getting first semester freshmen to realize that checking their work was important, that they needed to produce work in a timely fashion and that they had the ability to decipher their own mistakes, what changes should be planned for in the future to further enhance this experience for the student?

One of the reasons for using e-learning is to improve performance. A recent study has indicated that "learners have the highest positive attitudes toward multimedia instruction (mean is 5.93) and moderately positive attitudes toward instructor-lead learning (mean is 4.68),(3). The scale of values referenced previously is on a 7 point scale. Would a better attitude increase student performance in the subject matter? 
If we look at the definition of e-learning, this course already meets most of the requirements. All course material is on line and available over the web. $75 \%$ of the quizzes are given in electronic form. $100 \%$ of quizzes could easily be given electronically; it is just easier for the students to reference a piece of paper rather than having another open window on the monitor. The final exam is downloaded electronically. All quiz and exam solutions are currently uploaded (drop boxed) to a secure file server by the students upon completion. Homework solutions could easily be graded and returned electronically.

Might it make sense to produce the lecture/demonstration part of the course in electronic form that the student could re-play over and over? Could student-instructor interaction be handled electronically in an effective manner?

One of the concerns related to e-learning might be the loss of the tangential "information" that would be lost with a decrease in face to face time with the students. How does one get impress upon the student the value of ethics and academic integrity related to the engineering profession that is not specifically stated in the course outline, yet come up in class numerous times during the semester? Case in point would be the issue of simply filling in the summary sheet for coupled assignments with duplicate information rather than going back though the documentation to enter the computed values. Being sloppy in this regard; essentially falsifying information can get you fired in industry. In virtually every course that is taught, topics surface that are outside of the realm of the course outline, yet are important in the overall education of an engineering student.

One of the assignments in this course is an introductory assignment in the creation of charts and graphs using Excel. Rather than re-invent the wheel, students are directed to a Microsoft training website where there is an on-line tutorial on creating charts. This is comprised of two lessons with practice sessions and short tests. While this exercise was done in class, it was interesting to note how the better (more disciplined) students approached the exercise verses the poorer (less disciplined) student. Biased on simple observation, the author believes e-learning will separate the serious students from the ones that are simply putting in time. If the goal is to retain some of the lower performing students with the hope that eventually they will "see the light", an introductory course in computer methods might not be a good fit for an e-learning course, regardless of whether the student would prefer electronic over instructor lead instruction or not.

E-learning aside; and understanding that the current generation is "better connected than previous generations... ruthless in the expectations of convenience... intolerant of repetition... lacking a sense of self-initiative and evolving (or devolving) into menu driven thinkers"(4), what other changes could be made to this course accommodate their learning style?

At the start of this semester a fully formatted Excel spreadsheet that has areas for students to enter all of their grades; homework, quiz and exam was distributed to the students. This spreadsheet will display a projected grade as well as produce a graph that is automatically updated showing a trend of their progress. Now, one would think that since the students were taking a course that made heavy use of Excel, that the students would write their own spreadsheet and take some responsibility for keeping track of their own grade. Unfortunately 
that is not the case. It is easier to pester the instructor near the end of the semester and ask about their standing in the class. In the past when students have asked about their grade, the author has responded with "you should already know that as I have strongly suggested at various times during the semester that you develop a spreadsheet for exactly that purpose". Since it wasn't a graded assignment, it wasn't done by the student. The instructors response that doesn't go over big with students as their thought is; since the instructor is keeping track of the grades, why should I (the student) have to essentially duplicate the instructors work of doing the grade calculation? The idea (misguided as it might be) of providing a spreadsheet is that by making it convenient for the student to view their progress early on (they don't have the background to develop such a spreadsheet until later in the semester), that maybe they might realize they need to pick up the pace sooner rather than later. Realizing there are trade off's to be made and that you need to pick your battles with students, one would rather have them come to the conclusion on their own (with the help of a provided "tool") that they need to work a little smarter rather than try to bully them into doing more of what they might consider repetitious, boring work.

The question is how to take something such as the pre-formatted grade spread sheet that the student views as simply a "right" and a convenience; and turn it into a learning exercise? An idea might be to assign a project (late in the semester) were students were to dissect this spreadsheet and modify it for other classes, rather than building it from scratch. The general idea behind this type of an assignment would be to allow the student to see the usefulness of a tool and then actually want to modify it for another application. Such an assignment might not appear to be just another academic exercise but the production of a spreadsheet that is actually useful. In the process the student would reinforce prior learning by being able to apply prior concepts without feeling that they were simply doing more repetitious work.

This type of assignment might be carried farther. Allow students the freedom to create a spreadsheet for a fairly open ended problem with few formatting restriction. After collecting the file and any documentation redistribute it to a different student, with a revised problem specification that requires changes to the original work. This is usually an enlightening experience. File swapping problems have been used in our CAD courses in the past, but not been in a computer methods class. This might be worth attempting such an assignment on a trial basis.

In conclusion, it is probably important to realize that there is a generation gap between faculty and students. What might have been a successful teaching methodology years ago might not work with today's students. Courses must continually evolve over time to satisfy the requirements of the curriculum as well as the needs of the students. If students don't start a course of study with a sense of dedication and responsibility, it is still imperative that they develop that before they finish. It is quite possible that student definition of effective problem solving is figuring out how to short circuit the system. It might then be the instructors' responsibility to instill in these students the traditional work ethics and problem solving methodologies that will allow them to be successful in the field of engineering using different means than were used in the past. 
References

1. Christian Hipp and Veronica Addison, The Effects of Prior Computer Experiences in Considering Engineering Students Ability to Solve Open-Ended Problems, Proceedings of the 2007 ASEE Annual Conference \& Exhibition

2. Joan A. Ballantine, Patricia McCourt Larres and Peter Oyelere, Computer usage and the validity of selfassessed computer competence among first-year business students, Computers and Education 49 (4) (2007), pp. 976-990.

3. Shu-Sheng Liaw, Hsiu-Mel Huang and Gwo-Dong Chen, Surveying instructor and learner attitudes towards elearning, Computers and Education 49 (4) (2007), pp. 1066-1080.

4. Robert W. Wendover, Understanding the Millennium Mind, The Center for Generational Studies, wendover.gentrends.com. 